Glacier area and the variability of glacier change

Argha Banerjee ${ }^{1}$ and Reshama Kumari ${ }^{2}$

${ }^{1}$ Earth and Climate Science, Indian Institute of Science Education and Research, Pune, India ${ }^{2}$ Centre of Studies in Resources Engineering, IIT Bombay, India

Correspondence: Argha Banerjee <argha@iiserpune.ac.in>

This is the EarthARxiv preprint of an article that is under review for publication in Journal of Glaciology. 


\title{
Glacier area and the variability of glacier change
}

Argha Banerjee ${ }^{1}$, and Reshama Kumari ${ }^{2}$

${ }^{1}$ Earth and Climate Science, Indian Institute of Science Education and Research, Pune, India

${ }^{2}$ Centre of Studies in Resources Engineering, IIT Bombay, India

Correspondence: Argha Banerjee < argha@iiserpune.ac.in>

\begin{abstract}
Large-scale remote-sensing data on ice loss in the Himalaya and other glacierised regions indicate that the differences in glacier area do not significantly influence the glacier-to-glacier variability of the thinning rate. An analysis of the available data from several regions across the globe reveals another general feature of the recent shrinkage glaciers: the rate of area loss grows sub-linearly as a function of glacier area. These two general characteristics of recent glacier change data are shown to be consistent with each other when the well-known area-volume scaling relation for mountain glaciers is considered. These empirical trends may be helpful in benchmarking simulations of recent and future glacier shrinkage.
\end{abstract}

\section{INTRODUCTION}

The recent large-scale ice-loss pattern in the High Mountain Asia is characterised by a strong spatial inhomogeneity (Bolch et al., 2011; Scherler et al., 2011; Nuimura et al., 2012; Gardelle et al., 2013; Kääb et al., 2012, 2015; Vijay and Braun, 2016; Brun et al., 2017). Investigations of the factors driving the inhomogeneity have revealed the role of a spatially variable climate forcing (Rupper and Roe, 2008; Fujita and Nuimura, 2011; Yao et al., 2012; Mölg et al., 2014; Kumar et al., 2015), the variability of the sensitivity of mass balance to temperature change (Sakai and Fujita, 2017), and effects related to the insulating supraglacial debris layer that often covers portions of ablation zone of Himalayan glaciers (Scherler et al., 2011; Banerjee and Shankar, 2013; Banerjee, 2017). The abundance of supraglacial ponds/cliffs on the debris-covered glaciers that enhances melt rates locally (Sakai et al., 2000; Miles et al., 2016; Brun et al., 
2018), and that of moraine-dammed terminal lakes (King et al., 2018) are also possible factors contributing to the variable mass loss.

Apart from the above factors, which exert influence by altering the surface mass-balance forcing, various geometrical variables like slope, area, aspect and hypsometry of glaciers have also been investigated for their possible influences on the glacier-to-glacier variability of thinning rates. These studies have revealed, for example, a significant control of glacier slope on regional-scale glacier thinning rate distribution in the high mountain Asia (Salerno et al., 2017; Brun et al., 2018) or in the Alps (Huss, 2012; Fischer et al., 2015; Rabatel et al., 2016), with gently sloping glacier showing higher loss rates. These trends may be understood in terms of a larger climate sensitivity and response time of the gently sloping glaciers (Oerlemans, 2001). Interestingly, the above studies have also concluded that glacier thinning rates are largely independent of glacier area, despite area of the studied glaciers varying over several orders of magnitudes. In this letter, we compile evidence from existing remote-sensing data on glacier shrinkage to find another empirical relation between the rate of change of glacier area and the total area of the glacier. The area-independent thinning, and the specific form of dependence of the rate of area loss on the glacier area, are shown to be consistent with each other in the light of a well-known scaling relation between glacier area and volume (Bahr et al., $2015)$

\section{GLACIER AREA AND THE THINNING RATE}

Area-independent net specific mass balance of glaciers have been observed in the Swiss and french Alps (Fischer et al., 2015; Rabatel et al., 2016), although an earlier study from Swiss Alps (Paul and Haeberli, 2008) had reported a higher net specific mass loss on larger glaciers. The area-independent thinning rate of glaciers have also been observed in the Khumbu region of the Himalaya (Salerno et al., 2017). Strong evidence in favour of this trend in several glacierised regions of High Mountain Asia has recently been provided by an analysis of thinning data from more than 6000 glaciers larger than $2 \mathrm{~km}^{2}$ (Brun et al., 2018)

To illustrate the above trend, here we use recent large-scale $30 \mathrm{~m}$ resolution glacier elevation change data from more than 8300 glaciers in the Himalaya (Brun et al., 2017) that are larger than $0.25 \mathrm{~km}^{2}$ and has more than $50 \%$ data coverage. For these glaciers, glacier-wide mean thinning rate is plotted as a function of glacier area (Fig. 1a). Both the area-weighted mean thinning rate within different area classes, and the thinning rates of individual glaciers when plotted as a function of area, demonstrate that the thinning rate of glaciers in the Himalaya are relatively insensitive to the variability of glacier area. There is very 

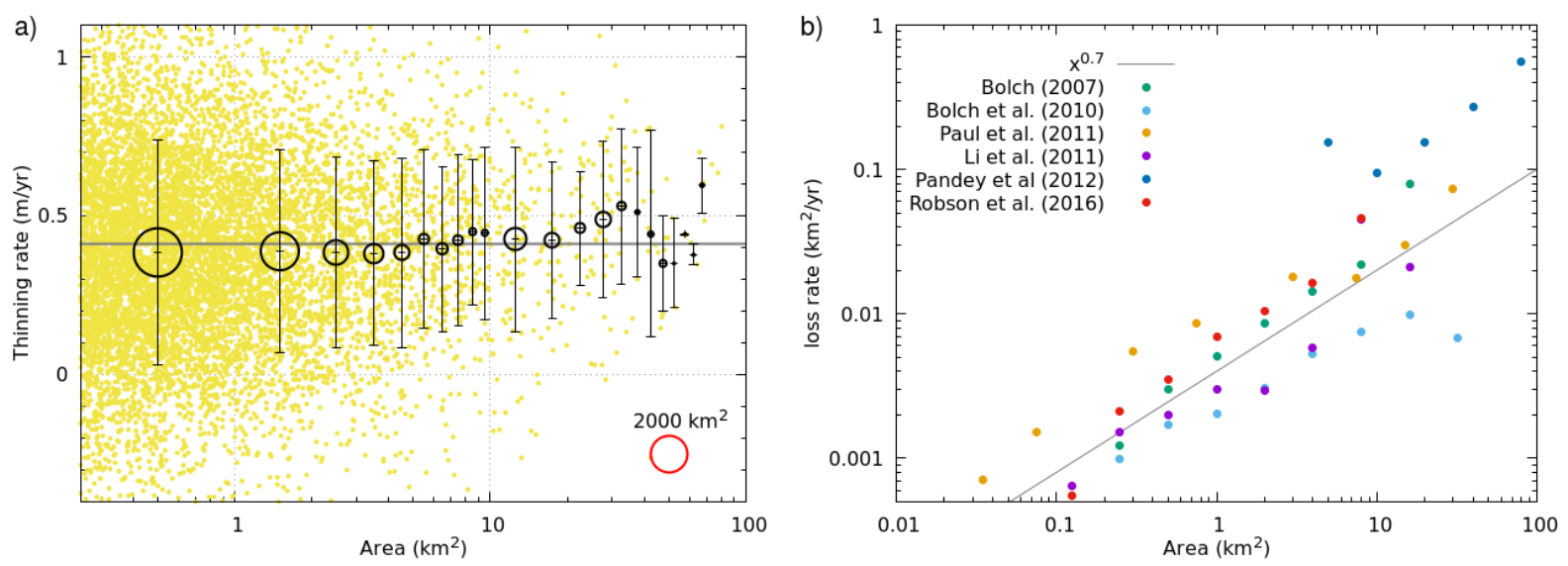

Fig. 1. (a) Glacier-wide mean thinning rates are binned according to the glacier area with bin size of $1 \mathrm{~km}^{2}$ below $10 \mathrm{~km}^{2}$ and $5 \mathrm{~km}^{2}$ above it. The area-weighted mean thinning rate for each of the bins are plotted with open black circles with vertical bars showing the corresponding standard deviation. The circle size denotes the total glacier area in the bin, with red open circle showing an area of $2000 \mathrm{~km}^{2}$ for scale. Thinning rate data for the individual glaciers studied are plotted with yellow dots. The gray horizontal line denotes the region-wide mean thinning rate as a reference. (b) Available data of the rate of area loss from six different regions in the world, binned according to glacier area, suggest an approximate power-law scaling of the rate of area loss as a function of glacier area, with a scaling exponent of $\sim 0.7$.

little systematic variation of thinning rates with glacier area, even as area varied by about two orders of magnitude among the glaciers considered here. Although the mean rate of thinning of glaciers larger than $10 \mathrm{~km}^{2}$ or so may be marginally higher than that for smaller glaciers (Fig. 1a). Overall, this analysis supports the observed area-independent thinning of glaciers in the Himalaya (Salerno et al., 2017; Brun et al., 2018) and the Alps (Fischer et al., 2015; Rabatel et al., 2016) as discussed above.

\section{GLACIER AREA AND THE RATE OF AREA LOSS}

To the best of our knowledge, any functional relationship, either empirical or theoretical, between glacier area and the rate of area change has not been discussed in the literature before. Here, we compiled six data sets from around the world (Bolch, 2007; Bolch et al., 2010; Li et al., 2011; Paul et al., 2011; Pandey et al., 2012; Robson et al., 2016) including that from the Himalaya and the Alps (Fig. 1b) to show that on an average, glaciers are losing area at rates that systematically grow with glacier area. Up to some noise, the functional dependence has an approximate sub-linear power-law form,

$$
\dot{A} \approx c_{1} A^{0.7} .
$$


Here, $A$ denotes glacier area, $\dot{A}$ is the rate of area loss, and $c_{1}$ is a dimensionful empirical constant that vary between regions. We are unable to provide any theoretical explanation of this empirical scaling behaviour.

\section{IMPLICATION OF THE AREA-VOLUME SCALING}

The intriguing trends of area-independent glacier thinning and a sub-linear power-law scaling of the rate of area loss with area, as discussed above, can be reconciled with the help of the area-volume scaling law for glaciers (Bahr et al., 2015) as follows.

The approximate scaling law relates glacier area and volume $(V)$ as,

$$
V=c_{2} A^{\gamma}
$$

where, $c_{2}$ is a dimensionful fitting parameter and $\gamma=1.375$ (Bahr et al., 2015). Using the fact that $V=h A$, a relation between mean thinning rate and glacier area can then be obtained,

$$
\dot{h}=c_{2} A^{\gamma-2} \dot{A} \text {. }
$$

The dependence of $\dot{h}$ on $A$ can now be derived from the above equation, if the dependence of $\dot{A}$ on $A$ is known, and that is provided by Eqn (1). Thus,

$$
\dot{h} \approx c_{1} c_{2} A^{\gamma-1.3} \text {. }
$$

With the power-law exponent $\gamma=1.375$, Eqn (4) would then imply that mean thinning rate of glaciers is nearly independent of, or rather, varying very weakly with glacier area $\left(\dot{h} \sim A^{0.075}\right)$.

Thus, the area-volume scaling law (Bahr et al., 2015), together with the empirical scaling of $\dot{A}$ with $A$, provide an understanding of the area-independent thinning rate as observed in the Himalaya (Salerno et al., 2017; Brun et al., 2018) or Alps (Fischer et al., 2015; Rabatel et al., 2016).

\section{DISCUSSIONS}

The above trends of area-independent thinning and rate of glacier area loss having a $\sim A^{0.7}$ behaviour could be useful in benchmarking glacier model simulations. A variety of approximate methods have been developed for efficient dynamic simulation a large number of glaciers. The simplest of these approaches (Immerzeel et al., 2010; Cogley, 2011; Radić and Hock, 2011; Kumar et al., 2015) usually relies on parameterising the glacier area change with area-volume scaling relation (Bahr et al., 2015). These models often ignore the changes in the hypsometry (Cogley, 2011; Kotlarski et al., 2010; Kumar et al., 2015). 
Approximate parameterisation of ice-flux effects using more complex optimisation schemes that mimic sliding or deformation of ice have been used to track the evolution of hypsometry (Immerzeel et al., 2013; Lutz et al., 2014; Kraaijenbrink et al., 2016). Purely empirical approaches to hypsometric adjustments also exist in the literature (Huss, 2010). Given the large number of such approximate methods, some general large-scale feature of transient retreating states of glaciers could be useful to validate the method chosen. The empirical trends of area-independent thinning and power-law scaling of the rate of area loss with glacier area, that are established above with the help of remote-sensing data and theoretical arguments, are potential candidates for such diagnostic criteria.

\section{ACKNOWLEDGEMENTS}

RK acknowledges the hospitality of IISER Pune for the duration of the study. The glacier thinning data from the Himalaya that is used in Fig. 1a are accessible at, https://doi.pangaea.de/10.1594/PANGAEA.876545 as provided by Brun et al. (2017). The glacier outlines used in this study are accessible from https://www.glims.org/RGI/.

\section{REFERENCES}

Bahr, D. B., Pfeffer, W. T., and Kaser, G. (2015). A review of volume-area scaling of glaciers. Reviews of Geophysics, 53(1), 95-140.

Banerjee, A., 2017. Brief communication: Thinning of debris-covered and debris-free glaciers in a warming climate. The Cryosphere, 11(1), 133-138.

Banerjee, A., and Shankar, R., 2013. On the response of Himalayan glaciers to climate change. Journal of Glaciology, $59(215), 480-490$.

Bolch, T. (2007). Climate change and glacier retreat in northern Tien Shan (Kazakhstan/Kyrgyzstan) using remote sensing data. Global and Planetary Change, 56(1-2), 1-12.

Bolch, T., and others (2010). A glacier inventory for the western Nyainqentanglha Range and the Nam Co Basin, Tibet, and glacier changes 1976-2009. The Cryosphere, 4(3), 419-433.

Bolch, T., Pieczonka, T., and Benn, D. I. (2011). Multi-decadal mass loss of glaciers in the Everest area (Nepal Himalaya) derived from stereo imagery. The Cryosphere, 5(2), 349-358.

Brun, F., Berthier, E., Wagnon, P., Kääb, A., and Treichler, D. (2017). A spatially resolved estimate of High Mountain Asia glacier mass balances from 2000 to 2016. Nature geoscience, 10(9), 668-673. 
Brun, F., Wagnon, P., Berthier, E., Shea, J. M., Immerzeel, W. W., Kraaijenbrink, P. D. A., Vincent, C., Reverchon, C., Shresta, D., and Arnaud, Y. (2018). Can ice-cliffs explain the "debris-cover anomaly"? New insights from Changri Nup Glacier, Nepal, Central Himalaya, The Cryosphere Discuss., https://doi.org/10.5194/tc-2018-38, in review.

Brun, F., Wagnon, P., Berthier, E., Jomelli, V., Maharjan, S. B., Shrestha, F., and Kraaijenbrink, P. D. A. Heterogeneous influence of glacier morphology on the mass balance variability in High Mountain Asia. Journal of Geophysical Research: Earth Surface.

Cogley, J. G. (2011). Present and future states of Himalaya and Karakoram glaciers. Annals of Glaciology, 52(59), 69-73.

Fischer, M., Huss, M., and Hoelzle, M. (2014). Surface elevation and mass changes of all Swiss glaciers 1980-2010. The Cryosphere, 9, 525-540.

Fujita, K., and Nuimura, T. (2011). Spatially heterogeneous wastage of Himalayan glaciers. Proceedings of the National Academy of Sciences, 108(34), 14011-14014.

Gardelle, J., Berthier, E., Arnaud, Y., and Kaab, A. (2013). Region-wide glacier mass balances over the PamirKarakoram-Himalaya during 1999-2011 (vol 7, pg 1263, 2013). The Cryosphere, 7(6), 1885-1886.

Huss, M., Jouvet, G., Farinotti, D., and Bauder, A. (2010). Future high-mountain hydrology: a new parameterization of glacier retreat. Hydrology and Earth System Sciences, 14(5), 815-829.

Huss, M. (2012). Extrapolating glacier mass balance to the mountain-range scale: the European Alps 1900-2100. The Cryosphere, 6, 713-727.

Immerzeel, W. W., Van Beek, L. P., and Bierkens, M. F. (2010). Climate change will affect the Asian water towers. Science, 328(5984), 1382-1385.

Immerzeel, W. W., Pellicciotti, F., and Bierkens, M. F. P. (2013). Rising river flows throughout the twenty-first century in two Himalayan glacierized watersheds. Nature geoscience, 6(9), 742.

Kääb, A., Treichler, D., Nuth, C., and Berthier, E. (2015). Brief Communication: Contending estimates of 2003-2008 glacier mass balance over the Pamir-Karakoram-Himalaya. The Cryosphere, 9(2), 557-564.

Kääb, A., Berthier, E., Nuth, C., Gardelle, J., and Arnaud, Y. (2012). Contrasting patterns of early twenty-firstcentury glacier mass change in the Himalayas. Nature, 488(7412), 495.

King, O., Dehecq, A., Quincey, D., and Carrivick, J. (2018). Contrasting geometric and dynamic evolution of lake and land-terminating glaciers in the central Himalaya. Global and Planetary Change, 167, 46-60.

Kotlarski, S., Jacob, D., Podzun, R., and Paul, F. (2010). Representing glaciers in a regional climate model. Climate dynamics, 34(1), 27. 
Kumar, P., Kotlarski, S., Moseley, C., Sieck, K., Frey, H., Stoffel, M., and Jacob, D. (2015). Response of KarakoramHimalayan glaciers to climate variability and climatic change: A regional climate model assessment. Geophysical Research Letters, 42(6), 1818-1825.

Kraaijenbrink, P. D. A., Bierkens, M. F. P., Lutz, A. F., and Immerzeel, W. W. (2017). Impact of a global temperature rise of 1.5 degrees Celsius on Asia's glaciers. Nature, 549(7671), 257.

Li, K., Li, Z., Gao, W., and Wang, L. (2011). Recent glacial retreat and its effect on water resources in eastern Xinjiang. Chinese Science Bulletin, 56(33), 3596-3604.

Lutz, A. F., Immerzeel, W. W., Shrestha, A. B., and Bierkens, M. F. P. (2014). Consistent increase in High Asia's runoff due to increasing glacier melt and precipitation. Nature Climate Change, 4(7), 587.

Miles, E. S., Willis, I. C., Arnold, N. S., Steiner, J., and Pellicciotti, F. (2017). Spatial, seasonal and interannual variability of supraglacial ponds in the Langtang Valley of Nepal, 1999-2013. Journal of Glaciology, 63(237), 88-105.

Mölg, T., Maussion, F., and Scherer, D. (2014). Mid-latitude westerlies as a driver of glacier variability in monsoonal High Asia. Nature Climate Change, 4(1), 68.

Naito, N., Nakawo, M., Kadota, T., and Raymond, C. F. (2000, September). Numerical simulation of recent shrinkage of Khuinbu Glacier, Nepal Himalayas. In Debris-covered Glaciers: Proceedings of an International Workshop Held at the University of Washington in Seattle, Washington, USA (Vol. 1315, p. 245).

Nuimura, T., Fujita, K., Yamaguchi, S., and Sharma, R. R. (2012). Elevation changes of glaciers revealed by multitemporal digital elevation models calibrated by GPS survey in the Khumbu region, Nepal Himalaya, 19922008. Journal of Glaciology, 58(210), 648-656.

Oerlemans, J. (2001). Glaciers and climate change. CRC Press.

Pandey, A. C., Nathawat, M. S., and Ghosh, S. (2012). Morphometric control on glacier area changes in the Great Himalayan Range, Jammu and Kashmir, India. Current Science, 1188-1193.

Paul, F., and Haeberli, W. (2008). Spatial variability of glacier elevation changes in the Swiss Alps obtained from two digital elevation models. Geophysical Research Letters, 35(21).

Paul, F., Frey, H., and Le Bris, R. (2011). A new glacier inventory for the European Alps from Landsat TM scenes of 2003: challenges and results. Annals of Glaciology, 52(59), 144-152.

Rabatel, A., Dedieu, J. P., and Vincent, C. (2016). Spatio-temporal changes in glacier-wide mass balance quantified by optical remote sensing on 30 glaciers in the French Alps for the period 1983-2014. Journal of Glaciology, 62(236), 1153-1166.

Radić, V., and Hock, R. (2011). Regionally differentiated contribution of mountain glaciers and ice caps to future sea-level rise. Nature Geoscience, $4(2), 91$. 
Robson, B. A., Hölbling, D., Nuth, C., Strozzi, T., and Dahl, S. O. (2016). Decadal Scale Changes in Glacier Area in the Hohe Tauern National Park (Austria) Determined by Object-Based Image Analysis. Remote Sensing, 8(1), 67.

Rupper, S., and Roe, G. (2008). Glacier changes and regional climate: a mass and energy balance approach. Journal of Climate, 21(20), 5384-5401.

Sakai, A., Takeuchi, N., Fujita, K., and Nakawo, M. (2000). Role of supraglacial ponds in the ablation process of a debris-covered glacier in the Nepal Himalayas. IAHS PUBLICATION, 119-132.

Sakai, A., and Fujita, K. (2017). Contrasting glacier responses to recent climate change in high-mountain Asia. Scientific reports, $7(1), 13717$.

Salerno, F., Thakuri, S., Tartari, G., Nuimura, T., Sunako, S., Sakai, A., and Fujita, K. (2017). Debris-covered glacier anomaly? Morphological factors controlling changes in the mass balance, surface area, terminus position, and snow line altitude of Himalayan glaciers. Earth and Planetary Science Letters, 471, 19-31.

Scherler, D., Bookhagen, B., and Strecker, M. R. (2011). Spatially variable response of Himalayan glaciers to climate change affected by debris cover. Nature geoscience, 4(3), 156-159.

Shea, J. M., and Immerzeel, W. W. (2016). An assessment of basin-scale glaciological and hydrological sensitivities in the Hindu Kush-Himalaya. Annals of Glaciology, 57(71), 308-318.

Vijay, S., and Braun, M. (2016). Elevation change rates of glaciers in the Lahaul-Spiti (Western Himalaya, India) during 2000-2012 and 2012-2013. Remote Sensing, 8(12), 1038.

Yao, T., and others (2012). Different glacier status with atmospheric circulations in Tibetan Plateau and surroundings. Nature climate change, 2(9), 663 . 